\title{
Diagnosis of Epipericardial Fat Necrosis on multimodality imaging in a pediatric patient: a case report and review of the literature
}

\author{
Lama Alomari $^{1}$, Ayman Khushaim ${ }^{2 *}$ \\ 1. Department of Emergency Medicine, Security Forces Hospital, Riyadh, Saudi Arabia \\ 2. Department of Radiology, McGill University Health Center, Montreal, Canada
}

* Correspondence: Ayman O Khushaim, Department of Radiology, McGill University Health Center, 1001 Decarie Blvd., Room B02.7006, Montreal, QC, H4A 3J1, Canada (₫Ayman.khushaim@mail.mcgill.ca)

Radiology Case. 2020 May; 14(5):16-24 :: $\quad$ DOI: $10.3941 /$ jrcr.v14i5.3971

\begin{abstract}
This is a case report of a 13-year-old male, presented to the Emergency Department complaining of a sudden onset left-sided pleuritic chest pain for 1 day. He was found to have a mass in the left Epipericardial fat with fat stranding and pleural effusion supporting the diagnosis of Epipericardial Fat Necrosis. The findings were established by Computed tomography and Ultrasound, and the final diagnosis was confirmed by Magnetic resonance imaging. Subsequently, the patient was discharged on analgesia; reassessment one-month later showed clinical improvement with no symptom recurrence. Repeated Ultrasound demonstrated a marked decrease in size and echogenicity of the mass. In this paper we review the clinical and radiological manifestations of Epipericardial fat necrosis and the different management approaches taken over the years.
\end{abstract}

\section{CASE REPORT}

\section{CASE REPORT}

A 13-year-old male, presented to the Emergency Department complaining of a sudden onset left-sided chest pain for 1 day. The pain was pleuritic in nature and worsened upon lying down. The boy gave history of a mild trauma while playing hockey 2 days prior to his presentation, but no history of fever. Upon examination, he looked uncomfortable and had shallow respirations with normal vital signs. Auscultation of the chest revealed decreased air entry over the left side. Laboratory investigations showed slightly elevated White Blood Cell count $(15.00 \mathrm{~g} / \mathrm{L}$ ), (normal range is between 5.0 to $10.0 \mathrm{~g} / \mathrm{L})$, minimal increase in Fibrinogen levels $(4.88 \mathrm{~g} / \mathrm{L})$, (normal range is between 2.0 to $4.0 \mathrm{~g} / \mathrm{L}$ ), and significant increase in C-Reactive Protein $(71.20 \mathrm{mg} / \mathrm{L}$ ), (normal level is less than $10 \mathrm{mg} / \mathrm{L}$ ). The patient was given Ibuprofen to relieve his pain and a chest x-ray (CXR) was ordered to rule out Pneumonia.

\section{Imaging findings:}

A posterior-anterior (PA) and lateral CXR was performed, PA view showed peripheral opacity involving the lower mid and inferior aspect of the left hemithorax (Figure 1a). The lateral costophrenic angle was clear. No airspace consolidation or pneumothorax. There were no rib changes. On the lateral view, there was a minimal undulation/thickening seen in the lower anterior chest (Figure 1b). 
Above-mentioned findings were non-specific to reach a conclusive diagnosis, so further imaging by chest computed tomography (CT) was suggested by the reporting radiologist. The treating physician consequently requested a CT chest to rule out Pulmonary Embolism (PE).

Chest CT scan PE protocol revealed in retrospect, fat stranding and fluid density in the left cardiophrenic sulcus on axial plane (Figure 2a). On coronal view, it demonstrated an ovoid/triangular-shaped mass in the left epipericardial fat that exhibited internal fat attenuation, fat stranding, hyperdense rim, and a central dense dot (Figure 2b). Sagittal view revealed fat stranding and fluid density in the left cardiophrenic sulcus (Figure 2c), with small left sided pleural effusion (not shown).

The above-stated findings were not picked up initially by the interpreting radiologist. Instead, the official report described a homogeneous soft tissue density with imprecise origin, possibly pleural based with no significant adjacent fat infiltration, and no evidence of PE. Consequently, further imaging by chest magnetic resonance imaging (MRI) was recommended.

The patient's symptoms improved with analgesia and he was discharged home and given outpatient follow up with general surgery.

The next day he came back with worsening pain and cardiology evaluation was requested. Electrocardiography illustrated normal sinus rhythm with early repolarization. Cardiac echo was normal as well. The next day ultrasound (US) of the lower chest was performed to further evaluate the mass in question and demonstrated an echogenic mass with areas of low echogenicity in the left cardiophrenic sulcus with small amount of reactive pericardial effusion (Figure 3a). Color Doppler showed an absence of central vascularity within the left cardiophrenic angle mass (Figure 3b). These findings were suggestive of a hematoma.

Later that day, MRI chest was done, T2W Fat saturation showed a heterogenous predominately bright $\mathrm{T} 2$ signal similar to fluid in the left cardiophrenic sulcus (Figure 4a), T1W inphase demonstrated an oval shaped mass layered with a rim of intermediate signal, inner wall of high signal (fat content) and a central low signal (linear strand) in the left cardiophrenic sulcus (Figure 4b), T1W out-of-phase sequence showed drop of the high signal in the mass compatible with fat content (Figure 4c), moderate left sided pleural effusion was noted with fluid signal intensity in the Epipericardium on T2W Fat saturation sequence (Figure 5) in keeping with Epipericardial fat necrosis (EPFN). A fat-containing tumor or a pleural collection (hematoma or infection) were considered unlikely. A follow-up US in one month was recommended to document improvement of findings.

\section{Management:}

The patient was discharged on non-steroidal antiinflammatory drugs (NSAIDs) and was given follow up US after 1 month.

\section{Follow-up:}

One-month post discharge the patient was seen, clinically improved with no pain recurrence. Gray-scale US of the lower chest demonstrated an interval decrease in size and echogenicity of the mass located in the left cardiophrenic sulcus (Figure 6) further supporting the diagnosis.

\section{DISCUSSION}

\section{Etiology \& Demographics:}

EPFN is a rare condition that was first described in 1957 [1]. It is considered a benign self-limited entity that takes place in the adipose tissue connecting the pericardial layer to the anterior thoracic wall [2].

Similar inflammatory processes can be seen in other body parts like the adipose tissue of the breast, pancreas in pancreatitis, and in epiploic appendagitis [3].

Ever since it was first described, only a few cases were reported in the literature. Hence the exact prevalence of EPFN remains unknown [4]. Consequently, it was theorized, that under-reporting of this entity could be attributed to misdiagnosis by Radiologists and Emergency Physicians whom are not familiar with it $[2,5]$.

In one case series, they looked at CT scans performed for adult patients presenting with atypical pleuritic chest pain in the Emergency department and found the incidence of EPFN to be $2.15 \%$ [6].

In a recent paper, it was suggested that the frequency of the radiologist properly reporting EPFN can be improved by increasing their awareness of the disease [7].

EPFN has been regarded a disease that generally affects healthy adults, but in the past couple of years, there have been case reports involving the pediatric age group. Reviewed literature revealed only 3 reported cases similar to our patient which reflects the importance of raising physicians' familiarity with this disease $[8,9,10]$.

There seems to be no obvious gender predilection as both males and females are affected equally [2], however in the case series mentioned earlier there was a 3:1 male predominance [6].

The etiology and exact pathogenesis of EPFN remain unknown. However, trauma and ischemia are known to cause necrosis in adipose tissue [3]. A couple of theories that were previously proposed include acute torsion of a vascular pedicle resulting in ischemic necrosis. Additionally, increased intrathoracic pressure due to heavy lifting or Valsalva's maneuver might in turn increase capillary pressure, leading to hemorrhagic necrosis $[3,11]$.

Obesity has been considered a risk factor for this entity primarily due to the increased volume of pericardial fat associated with it, but in the cases reported over the decades 
only $42 \%$ were regarded as moderately obese [11]. Pathologies commonly suggested to associate with EPFN include dyslipidemia and Cushing syndrome, in addition to history of steroid therapy [5].

\section{Clinical \& Imaging findings:}

The main presenting complaint of EPFN is an acute pleuritic chest pain that occurs in otherwise healthy individuals [2,3], the pain usually lasts from days to weeks, but it lingered for 1 year in one case [3]. Associated symptoms consist mainly of shortness of breath, dizziness, syncope, and diaphoresis [4]. Review of 24 cases in the literature revealed that the pain was left sided in 16 patients, while 5 patients described a right sided chest pain, the remaining 3 however did not give a specific description of their pain [11]

It was theorized that the reason for changing localization of the pain was due to the different location of the fat necrosis itself and consequently EPFN may mimic other pathologies such as Myocardial Infarction (MI), PE, or Acute Pericarditis $[2,5]$.

Vital signs and physical examination are usually within normal limits, except for mild tachycardia in some occasions [2].

Cardiac work up including electrocardiograms and cardiac enzymes and other laboratory investigations are generally unremarkable [2], with the exception of minimal rise in inflammatory markers as was seen in one case [7]. Additionally, a mildly elevated D-dimer was described in 3 different cases $[4,5,7]$.

PA views of CXR usually depict an opacity overlying the cardio-phrenic angle on the same side of the chest pain with an ipsilateral pleural effusion [2].

Chest CT is considered the imaging modality of choice, typical CT findings of EPFN reveal an encapsulated fatcontaining lesion, fat stranding of surrounding soft tissue, and associated pericardial thickening as inflammatory changes, in addition to an ipsilateral pleural effusion $[2,3]$.

Imaging analysis of the patients presented in the same case series acknowledged that $80 \%$ of the lesions were left sided. In addition, $80 \%$ of the patients presented with an ipsilateral pleural effusion, $65 \%$ and $45 \%$ demonstrated pericardial thickening and atelectasis respectively [6].

To our knowledge, the first time an MRI was reported in EPFN diagnosis was in 2005 following a CT, the findings in the MRI confirmed the presence of fat contents and demonstrated hypointense strands within the lesion [3].

In a recent case report, a cardiac MRI was performed and established the presence of a well-defined nodular lesion, located outside the pericardium in relation to the right ventricular apex. It demonstrated a hypersignal on T1 and T2, loss of signal in fat saturation sequences, and no late enhancement. The lesion was defined by a regular halo that presented hypersignal on $\mathrm{T} 2$, late enhancement, and did not saturate on fat saturation sequences [12].

One case reports US as a potential diagnostic modality especially in pediatric patients, EPFN manifested on US as an ovoid mass with absent internal blood flow, demonstrating a hyperechoic center and a hypoechoic periphery [10].

Review of the published pediatric cases exhibited similar clinical and imaging findings and disease course to their adult counterpart $[8,9,10]$.

\section{Treatment \& Prognosis:}

Historically, EPFN was managed surgically with subsequent analysis of the excised lesion to rule out oncologic pathologies [11]. That remained the standard approach until 2005, when the first case of EPFN with successful conservative management was published, and a follow up CT scan was performed to demonstrate resolution of the lesion post treatment. [3].

Conservative management consists of symptomatic relief with NSAIDs, and a follow up imaging $4-8$ weeks after the initial presentation is indicated to document the resolution of the radiographic findings and exclude neoplastic processes [2]. A control CT will typically depict reduction in the size of the mass along-side clearance of the inflammatory changes [5]. A follow up US can also be used to showcase the healing process [10].

In the case series referenced in this paper, all of the involved patients showed absolute clearance of CT findings and pain relief around 2 months after treatment initiation [6].

Prognosis is very good as this disease is self-limiting with symptoms generally clearing up within a few days and complete resolution of radiological findings is witnessed in the upcoming weeks to months [7].

\section{Differential Diagnoses:}

Based on the clinical presentation of EPFN, we hinted at the possibility of it mimicking other entities such as MI, PE, and Acute Pericarditis. Hence the importance of including these serious conditions in the differential diagnosis. However, when it comes to the imaging findings, other conditions resembling EPFN's appearance on imaging modalities come to mind.

In one case report, the imaging findings resembled those of a liposarcoma, consequently, the patient underwent an unnecessary invasive thoracotomy in order to perform histopathology on the suspected lesion which was concluded to constitute fat necrosis with no evidence of tumor presence [3].

Previously, there was a confusion in distinguishing EPFN from other fat containing lesions, such as lipoma or liposarcoma due to the similarities in their appearance, 
especially to those who lack expertise and familiarity with the diagnosis $[3,11]$.

In a recent report, the findings on CT scan were not recognized due to lack of awareness of the reporting radiologist. Instead the initial interpretation was a Morgagni hernia containing omental fat given the proximity of the lesion to the diaphragm [10].

Other differential diagnostic consideration consists of teratoma or lipoblastoma. However, the sudden onset of chest pain, coupled with the spontaneous resolution should lead to proper differentiation between EPFN and other diseases [10].

Pericardial lipomas are benign lesions that most commonly grow in a subtle way, therefore resulting in a few symptoms. They appear echogenic on US. CT findings constitute of a homogeneous fat containing lesion with no enhancing component. MRI features include non-enhancing lesions that demonstrate high signal on T1-weighted images and intermediate to high signal intensity on T2-weighted images. Homogenous drop in signal seen in fat-saturated sequences confirm the fat content [13].

Teratomas are germ cell tumors that can develop in the pericardium. These tumors must contain at least two germ cell layers. On US, a teratoma appears as a heterogeneous and complex multilocular cystic mass with echogenic foci representing calcifications. It is commonly associated with pericardial effusion. CT features include a well-circumscribed, heterogeneous, predominantly cystic, multilocular mass; calcifications are common, and fat is seen in about $75 \%$ of patients [13]. MRI shows a heterogeneous, encapsulated, complex cystic mass that exhibits $\mathrm{T} 1$ hypointense signal, $\mathrm{T} 1$ hyperintense signal if proteinaceous and $\mathrm{T} 2$ hyperintense signal [14].

Lipoblastomas are uncommon mesenchymal tumors that present typically before 3 years of age [15]. US shows an echogenic mass. CT predominantly exhibits a hypodense mass, and can demonstrate septations of soft-tissue density. Its internal signal on MRI follows the subcutaneous fat signal and therefore appears T1 hyperintense, and T2 intermediately intense to hyperintense. Characteristically, these tumors exhibit septations and intra-tumoral streaks that represent the fibrovascular network. In some occasions, cystic changes may be seen [13].

Liposarcomas are slow-growing tumors that are usually large at presentation [13]. They have been described on US as heterogeneous, multilobulated, typically well-defined lesions; however, recognition of fat as increased echogenicity is usually challenging [16]. CT and MRI both demonstrate a large heterogeneous, predominantly fat containing lesion, with areas of soft-tissue enhancement [15].

Morgagni hernia is an uncommon congenital diaphragmatic defect defined as anterior herniation between the pars costalis and pars sternalis in the cardiophrenic angle [17]. US can be helpful in detecting solid organs that have been herniated [18]. When the herniated part is the omentum, it can be differentiated from EPFN on both CT and MRI by recognition of omental vessels within the herniated mass; this is best assessed on coronal reformat [17].

\section{TEACHING POINT}

Epipericardial fat necrosis (EPFN) is a self-limited benign entity that presents in both adults and pediatric population with acute pleuritic chest pain. This condition can be diagnosed with either CT or US but CT is regarded as the modality of choice with typical features include an encapsulated fat-containing lesion, fat stranding, pericardial thickening, and an ipsilateral pleural effusion; However, when there is diagnostic uncertainty, MRI can confirm the diagnosis.

\section{REFERENCES}

1. Jackson RC, Clagett OT, McDonald JR. Pericardial fat necrosis: report of three cases. J Thorac Surg. 1957; 33:723729. PMID: 13429689.

2. Giassi KS, Costa AN, Bachion GH, et al. Epipericardial fat necrosis: an underdiagnosed condition. Br J Radiol. 2014 Jun;87(1038):20140118. PMID: 24707937.

3. Pineda V, Cáceres J, Andreu J, Vilar J, Domingo ML. Epipericardial fat necrosis: radiologic diagnosis and followup. AJR Am J Roentgenol. 2005 Nov;185(5):1234-6. PMID: 16247140 .

4. Nguyen DN, Tran CD, Rudkin SM, Mueller JS, Hartman MS. Epipericardial fat necrosis: Uncommon cause of acute pleuritic chest pain. Radiol Case Rep. 2018 Sep 25;13(6):1276-1278. PMID: 30275921.

5. Celikkanat S, Hamcan S, Bozlar U, Tasar M. Epipericardial fat necrosis clinically mimicking pulmonary embolism: computed tomographic angiography findings. Am J Emerg Med. 2016 Oct;34(10):2056.e5-2056.e6. PMID: 27049795.

6. Giassi KS, Costa AN, Bachion GH, Kairalla RA, Filho JR. Epipericardial fat necrosis: who should be a candidate? Am J Roentgenol. 2016;207:773-777. PMID: 27351235.

7. Haq S, Wilson MP, Manca D. Epipericardial fat necrosis: an uncommon self-limiting cause of pleuritic chest pain. CMAJ. 2019 Dec 16;191(50):E1378-E1381. PMID: 31844022 .

8. Bolourchi M, Renjen P, Kovanlikaya A, et al. Epipericardial Fat Pad Necrosis-A Rare Cause of Chest Pain in an Adolescent. Pediatr Emerg Care. 2018 Dec 21. PMID: 30586039 .

9. Aiga S, Hosoya Y, Nozaki T, Matsusako M. Epipericardial fat necrosis: Rare cause of chest pain in children. Pediatr Int. 2018 Aug;60(8):767-768. PMID: 30160038. 
10. Artunduaga M, Fuqua BL, Pierry C, Soto Giordani GA, Roman-Colon AM. Imaging diagnosis of Epipericardial fat necrosis in children. Pediatr Radiol. 2020 Feb;50(2):285-288. PMID: 31529148.

11. Runge T, Greganti MA. Epipericardial fat necrosis -a rare cause of pleuritic chest pain: case report and review of the literature. Arch Med Sci. 2011 Apr;7(2):337-41. PMID: 22291777.

12. Neto A, Seabra D, Moreno N, Magalhães S, Pires L, Pinto P. Epipericardial fat necrosis as a differential diagnosis of chest pain-A case report. Echocardiography. 2020 Jan;37(1):132-134. PMID: 31872908.

13. Restrepo CS, Vargas D, Ocazionez D, Martínez-Jiménez S, Betancourt Cuellar SL, Gutierrez FR. Primary pericardial tumors. Radiographics. 2013 Oct;33(6):1613-30. PMID: 24108554.

14. Ghadimi Mahani M, Lu JC, Rigsby CK, Krishnamurthy R, Dorfman AL, Agarwal PP. MRI of pediatric cardiac masses. AJR Am J Roentgenol. 2014 May;202(5):971-81. PMID: 24758649 .
15. Pruente R, Restrepo CS, Ocazionez D, Suby-Long T, Vargas D. Fatty lesions in and around the heart: a pictorial review. Br J Radiol. 2015 Jul;88(1051):20150157. PMID: 25950727.

16. Murphey MD, Arcara LK, Fanburg-Smith J. From the archives of the AFIP: imaging of musculoskeletal liposarcoma with radiologic-pathologic correlation. Radiographics. 2005 Sep-Oct;25(5):1371-95. PMID: 16160117.

17. Sandstrom CK, Stern EJ. Diaphragmatic hernias: a spectrum of radiographic appearances. Curr Probl Diagn Radiol. 2011 May-Jun;40(3):95-115. PMID: 21440192.

18. Chavhan GB, Babyn PS, Cohen RA, Langer JC. Multimodality imaging of the pediatric diaphragm: anatomy and pathologic conditions. Radiographics. 2010 Nov;30(7):1797-817. PMID: 21057121.

\section{FIGURES}

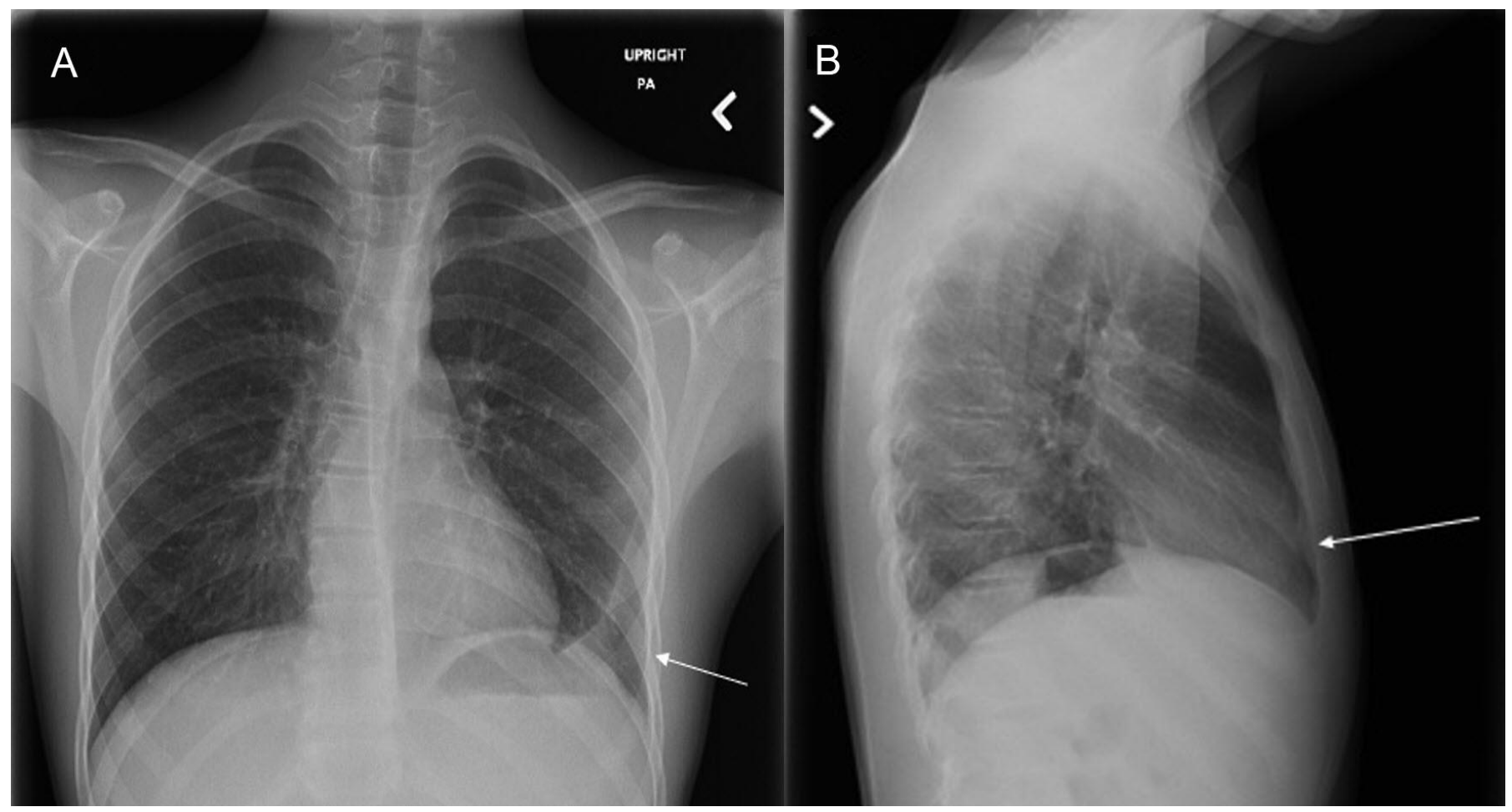

Figure 1: A 13-year-old male with Epipericardial fat necrosis.

Technique: 1a, 1b. Posterior-anterior (PA) and lateral chest X-ray was performed.

Findings:

a) There is a peripheral opacity involving the lower mid and inferior aspect of the left hemithorax (arrow). The lateral costophrenic angle is clear. No airspace consolidation or pneumothorax. There are no rib changes.

b) There is a minimal undulation/thickening seen in the lower anterior chest (arrow). 


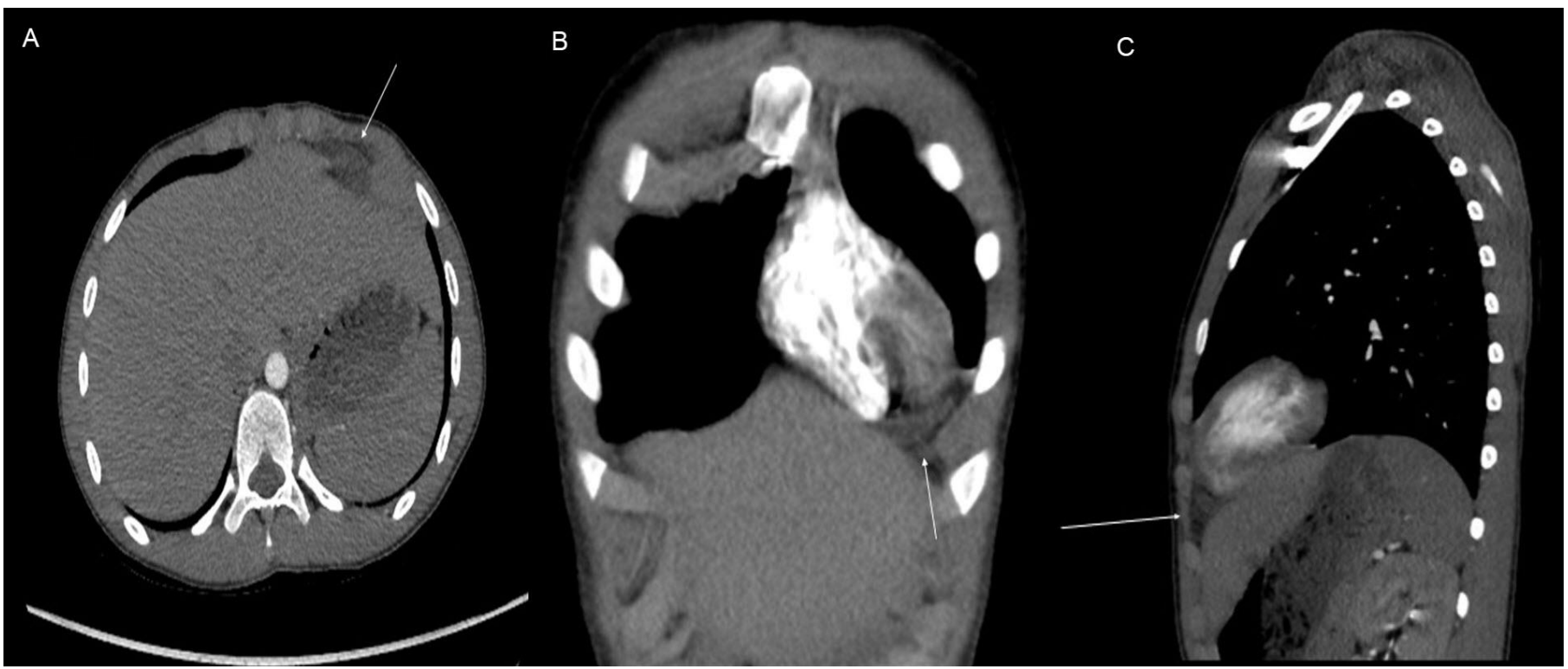

Figure 2: A 13-year-old male with Epipericardial fat necrosis.

Technique: 2a, 2b, 2c. (GE Healthcare Discovery CT750 HD) Chest CT scan pulmonary embolism protocol with intravenous injection of contrast material, $95 \mathrm{ml}$ Omnipaque $300^{\mathrm{TM}}$ (iohexol), $120 \mathrm{Kvp}, 150 \mathrm{mAs}, 1.25 \mathrm{~mm}$ slice thickness.

\section{Findings:}

a) Axial CT scan of the chest with intravenous injection of contrast material soft tissue window demonstrates a fat stranding and fluid density seen in the left cardiophrenic sulcus (arrow).

b) Coronal CT scan of the chest with intravenous injection of contrast material soft tissue window demonstrates an ovoid/triangular-shaped mass in the left epipericardial fat that demonstrate internal fat attenuation, fat stranding and a hyperdense rim and a central dense dot (arrow). It measures $4.1 \times 2.5 \times 2.3 \mathrm{~cm}$.

c) Sagittal CT scan of the chest with intravenous injection of contrast material soft tissue window demonstrates a fat stranding and fluid density seen in the left cardiophrenic sulcus (arrow). There is a small left sided pleural effusion (not shown).

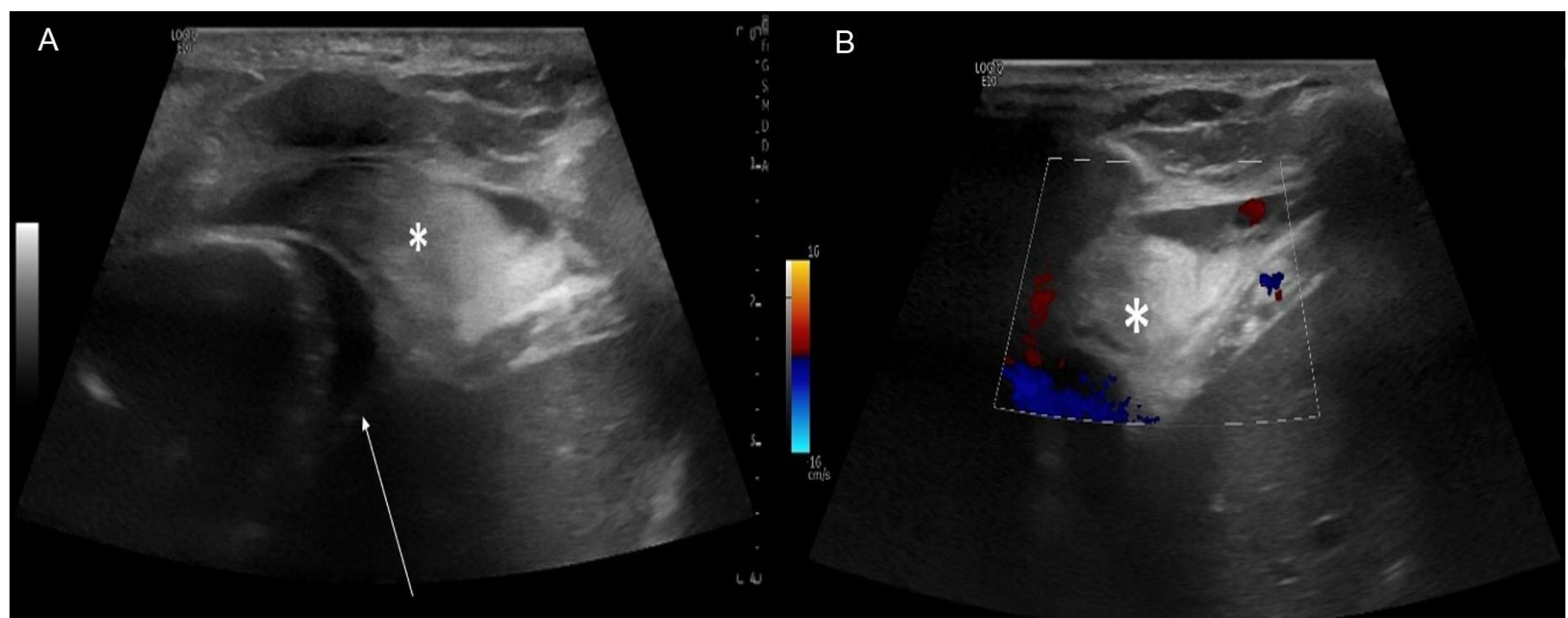

Figure 3: A 13-year-old male with Epipericardial fat necrosis.

Technique: 3a, 3b. Ultrasound performed on GE LOGIC E10 with L2-9 transducer at a frequency of 9.0 MHz.

\section{Findings:}

a) A longitudinal gray-scale ultrasound of the lower chest demonstrates an echogenic mass with areas of low echogenicity seen in the left cardiophrenic sulcus (asterisk). It measures 3.6 × $1.3 \times 3.6 \mathrm{~cm}$. Also, a small amount of reactive pericardial effusion is noted (arrow).

b) A longitudinal color doppler ultrasound of the lower chest demonstrates an absence of central vascularity within the left cardiophrenic angle mass (asterisk). 


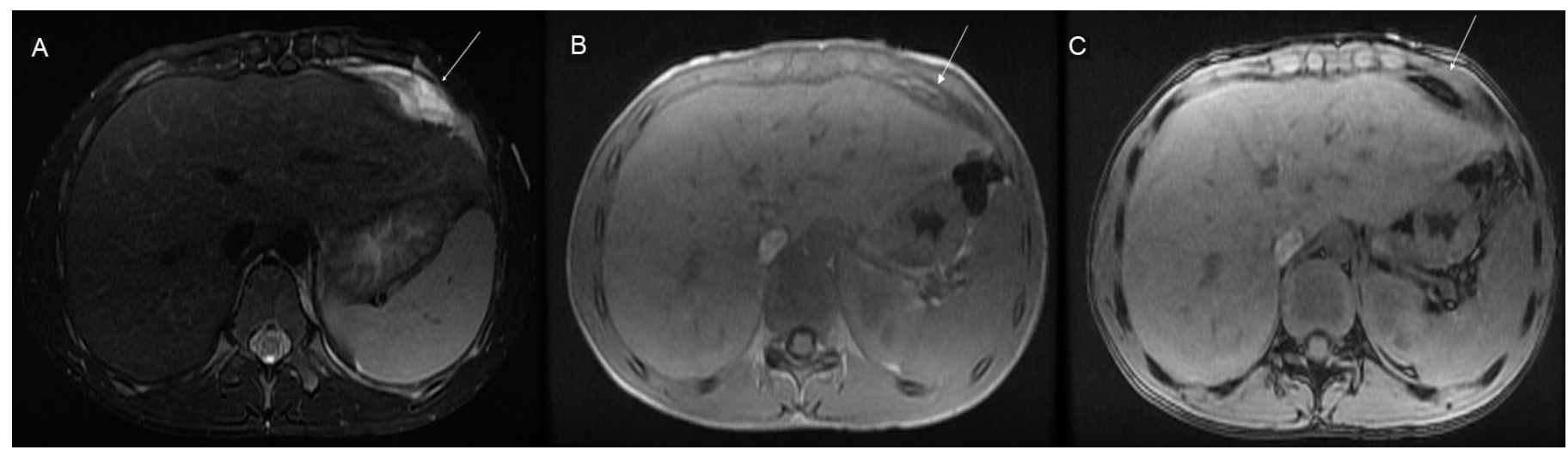

Figure 4: A 13-year-old male with Epipericardial fat necrosis.

Technique:

4a; MRI 1.5T; T2W Fat sat axial $(\mathrm{TE}=105.1 \mathrm{~ms}, \mathrm{TR}=6923 \mathrm{~ms}) ; 4.0 \mathrm{~mm}$ slice thickness.

$4 \mathrm{~b}$; MRI 1.5T; T1W in-phase axial $(\mathrm{TE}=4.6 \mathrm{~ms}, \mathrm{TR}=220 \mathrm{~ms}) ; 4.0 \mathrm{~mm}$ slice thickness.

4c; MRI 1.5T; T1W out-of-phase axial $(\mathrm{TE}=2.28 \mathrm{~ms}, \mathrm{TR}=220 \mathrm{~ms}) ; 4.0 \mathrm{~mm}$ slice thickness.

Findings:

a) An axial MRI demonstrates a heterogenous predominately bright T2 signal similar to fluid seen in the left cardiophrenic sulcus (arrow).

b) Axial MRI demonstrates an oval shaped mass layered with a rim of intermediate signal, inner wall of high signal (fat content) and a central low signal (linear strand) seen in the left cardiophrenic sulcus (arrow). It measures $1.0 \times 3.0 \times 1.2 \mathrm{~cm}$.

c) Axial MRI demonstrates an oval-shaped mass seen in the left cardiophrenic sulcus that showed drop of the high signal in outof-phase sequence compatible with fat content (arrow).

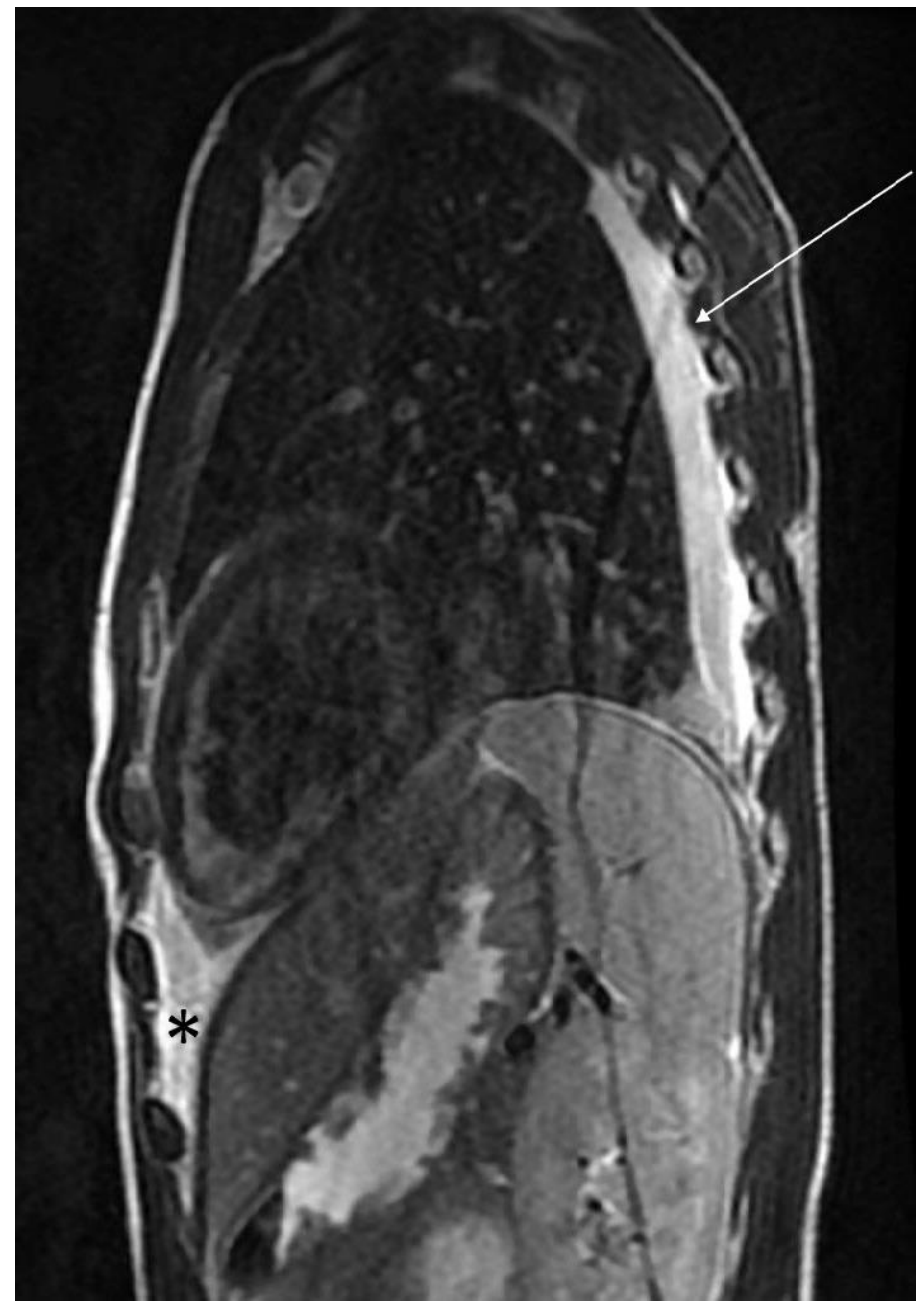

Figure 5 (left): A 13-year-old male with Epipericardial fat necrosis.

Technique: MRI 1.5T; T2W Fat sat sagittal $(\mathrm{TE}=102 \mathrm{~ms}$, $\mathrm{TR}=7272 \mathrm{~ms}$ ); $4.0 \mathrm{~mm}$ slice thickness.

Findings: Moderate left sided pleural effusion is noted (arrow). Fluid signal intensity seen in the Epipericardium (asterisk). 


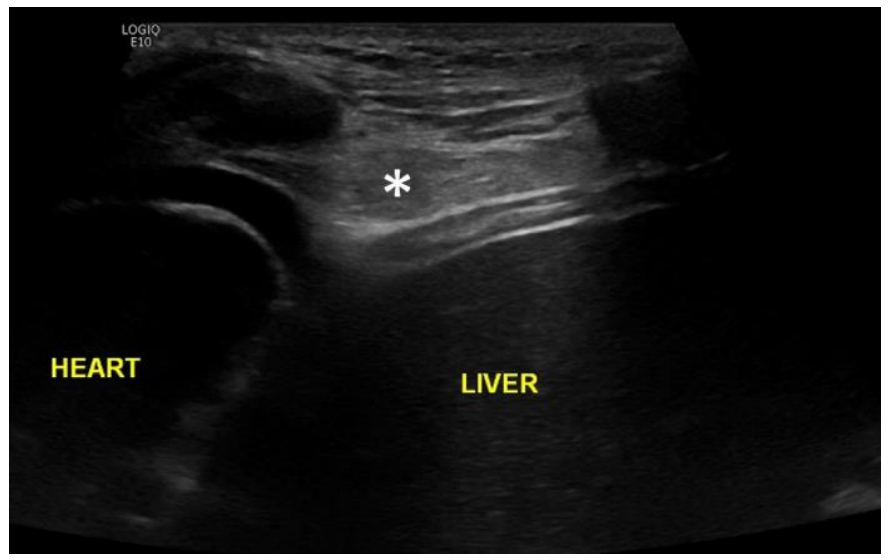

Figure 6 (left): A 13-year-old male with Epipericardial fat necrosis.

Technique: Ultrasound performed on GE LOGIC E10 with L2-9 transducer at a frequency of 9.0 $\mathrm{MHz}$.

Findings: A longitudinal gray-scale ultrasound of the lower chest demonstrates an interval decrease in size and echogenicity of the mass seen in the left cardiophrenic sulcus (asterisk). It measures $0.7 \times 2.3 \times 1.8 \mathrm{~cm}$.

\begin{tabular}{|c|c|}
\hline Etiology & $\begin{array}{l}\text { - Remain unknown. } \\
\text { - Proposed theories include: } \\
\text { 1. Acute torsion of a vascular pedicle. } \\
\text { 2. Heavy lifting or Valsalva's maneuver. } \\
\text { 3. Trauma }[3,11] \text {. }\end{array}$ \\
\hline Incidence & $\begin{array}{l}\text { - The exact prevalence remains unknown [4]. } \\
\text { - } 2.15 \%[6] \text {. }\end{array}$ \\
\hline Gender ratio & $\begin{array}{l}\text { - There is no gender predilection [2]. } \\
\text { - } 3: 1 \text { male predominance [6]. }\end{array}$ \\
\hline Age predilection & Mainly affects healthy adults, but there were 3 reported cases in the pediatric population $[8,9,10]$. \\
\hline Risk factors & $\begin{array}{l}\text { - Obesity [11]. } \\
\text { - Dyslipidemia, Cushing syndrome, history of steroid therapy [5] }\end{array}$ \\
\hline Treatment & $\begin{array}{l}\text { - Previously managed surgically [11]. } \\
\text { - Conservative management consists of Non-steroidal anti-inflammatory drugs (NSAIDs) and a } \\
\text { follow up imaging } 4-8 \text { weeks later to document the resolution of the radiographic findings [2]. }\end{array}$ \\
\hline Prognosis & $\begin{array}{l}\text { - Good prognosis. } \\
\text { - Symptoms clear up within a few days [7]. } \\
\text { - Radiological findings resolve in weeks to months [7]. }\end{array}$ \\
\hline Findings on imaging & $\begin{array}{l}\text { - Chest X-rays: an opacity overlying the cardio-phrenic angle on the same side of the chest pain with } \\
\text { an ipsilateral pleural effusion [2]. } \\
\text { - Chest CT: an encapsulated fat-containing lesion, fat stranding of surrounding soft tissue, pericardial } \\
\text { thickening, and an ipsilateral pleural effusion [2,3]. } \\
\text { - Chest US: an ovoid mass with absent internal blood flow, demonstrating a hyperechoic center and a } \\
\text { hypoechoic periphery [10]. } \\
\text { - Chest MRI: a well-defined nodular lesion that demonstrates a hypersignal on T1 and T2, and loss } \\
\text { of signal in fat saturation sequences with no late enhancement [12]. }\end{array}$ \\
\hline
\end{tabular}

Table 1: Summary table for Epipericardial Fat Necrosis (EPFN). 


\begin{tabular}{|c|c|c|c|}
\hline $\begin{array}{l}\text { Differential } \\
\text { diagnoses }\end{array}$ & US & CT & MRI \\
\hline $\begin{array}{l}\text { Epipericardial } \\
\text { fat necrosis } \\
\text { (EPFN) }\end{array}$ & $\begin{array}{l}\text { An ovoid mass with absent } \\
\text { internal blood flow, } \\
\text { demonstrating a hyperechoic } \\
\text { center and a hypoechoic } \\
\text { periphery [10]. }\end{array}$ & $\begin{array}{l}\text { An encapsulated fat-containing } \\
\text { lesion, fat stranding of } \\
\text { surrounding soft tissue, and } \\
\text { associated pericardial thickening } \\
\text { as inflammatory changes, in } \\
\text { addition to an ipsilateral pleural } \\
\text { effusion }[2,3] \text {. }\end{array}$ & $\begin{array}{l}\text { A well-defined nodular lesion, } \\
\text { located outside the pericardium in } \\
\text { relation to the right ventricular apex. } \\
\text { It demonstrates a hypersignal on } \mathrm{T} 1 \\
\text { and } \mathrm{T} 2 \text {, loss of signal in fat saturation } \\
\text { sequences, and no late enhancement } \\
{[12] \text {. }}\end{array}$ \\
\hline Lipoma & An echogenic mass [13]. & $\begin{array}{l}\text { A homogeneous fat containing } \\
\text { lesion with no enhancing } \\
\text { component [13]. }\end{array}$ & $\begin{array}{l}\text { Non-enhancing lesions that } \\
\text { demonstrate high signal on T1- } \\
\text { weighted images and intermediate to } \\
\text { high signal intensity on T2-weighted } \\
\text { images. Homogenous drop in signal } \\
\text { seen in fat-saturated sequences } \\
\text { confirm the fat content [13] }\end{array}$ \\
\hline Teratoma & $\begin{array}{l}\text { A heterogeneous and complex } \\
\text { multilocular cystic mass with } \\
\text { echogenic foci representing } \\
\text { calcifications. It is commonly } \\
\text { associated with pericardial } \\
\text { effusion [13]. }\end{array}$ & $\begin{array}{l}\text { A well-circumscribed, } \\
\text { heterogeneous, predominantly } \\
\text { cystic, multilocular mass; } \\
\text { calcifications are common, and } \\
\text { fat is seen in about } 75 \% \text { of } \\
\text { patients [13]. }\end{array}$ & $\begin{array}{l}\text { A heterogeneous, encapsulated, } \\
\text { complex cystic mass that exhibits T1 } \\
\text { hypointense signal, T1 hyperintense } \\
\text { signal if proteinaceous and T2 } \\
\text { hyperintense signal [14]. }\end{array}$ \\
\hline Lipoblastoma & An echogenic mass [13]. & $\begin{array}{l}\text { A hypodense mass, and can } \\
\text { demonstrate septations of soft- } \\
\text { tissue density [13]. }\end{array}$ & $\begin{array}{l}\text { A hyperintense lesion on } \mathrm{T} 1 \text {, and } \\
\text { intermediately intense to } \\
\text { hyperintense on T2. Also exhibits } \\
\text { septations and intra-tumoral streaks } \\
\text { that represent the fibrovascular } \\
\text { network. In some occasions, cystic } \\
\text { changes may be seen [13]. }\end{array}$ \\
\hline Liposarcoma & $\begin{array}{l}\text { A heterogeneous, } \\
\text { multilobulated, typically well- } \\
\text { defined lesion; however, } \\
\text { recognition of fat as increased } \\
\text { echogenicity is usually } \\
\text { challenging [16]. }\end{array}$ & $\begin{array}{l}\text { A large heterogeneous, } \\
\text { predominantly fat containing } \\
\text { lesion, with areas of soft-tissue } \\
\text { enhancement [15]. }\end{array}$ & $\begin{array}{l}\text { A large heterogeneous, } \\
\text { predominantly fat containing lesion, } \\
\text { with areas of soft-tissue enhancement } \\
{[15] .}\end{array}$ \\
\hline Morgagni hernia & $\begin{array}{l}\text { Helpful in detecting solid } \\
\text { organs that have been } \\
\text { herniated [18]. }\end{array}$ & $\begin{array}{l}\text { When the herniated part is the } \\
\text { omentum, it can be differentiated } \\
\text { from EPFN by recognition of } \\
\text { omental vessels within the } \\
\text { herniated mass; this is best } \\
\text { assessed on coronal reformat [17]. }\end{array}$ & $\begin{array}{l}\text { When the herniated part is the } \\
\text { omentum, it can be differentiated } \\
\text { from EPFN by recognition of } \\
\text { omental vessels within the herniated } \\
\text { mass; this is best assessed on coronal } \\
\text { reformat [17]. }\end{array}$ \\
\hline
\end{tabular}

Table 2: Differential diagnosis table for Epipericardial Fat Necrosis (EPFN).

\section{ABBREVIATIONS}

$\mathrm{CT}=$ Computed tomography

CXR $=$ Chest $\mathrm{X}$-ray

$\mathrm{EPFN}=$ Epipericardial fat necrosis

MI = Myocardial infarction

MRI = Magnetic resonance imaging

NSAIDs $=$ Non-steroidal anti-inflammatory drugs

$\mathrm{PA}=$ Posterior-anterior

$\mathrm{PE}=$ Pulmonary embolism

\section{KEYWORDS}

Epipericardial fat necrosis; pericardium; pleuritic chest pain; Computed Tomography; Ultrasound; Magnetic Resonance Imaging; pediatrics

\section{Online access}

This publication is online available at: www.radiologycases.com/index.php/radiologycases/article/view/3971

\section{Peer discussion}

Discuss this manuscript in our protected discussion forum at: www.radiolopolis.com/forums/JRCR

\section{Interactivity}

This publication is available as an interactive article with scroll, window/level, magnify and more features. Available online at www.RadiologyCases.com
Published by EduRad

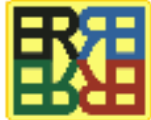

www.EduRad.org 